\section{Cooperative regulation in development by SMRT and FOXP1}

\author{
Kristen Jepsen, ${ }^{1,5}$ Anatoli S. Gleiberman, ${ }^{2}$ \\ Can Shi, ${ }^{3}$ Daniel I. Simon, ${ }^{3}$ and \\ Michael G. Rosenfeld ${ }^{1,4}$
}

${ }^{1}$ Department of Medicine, Howard Hughes Medical Institute, University of California at San Diego, School of Medicine, La Jolla, California 92093, USA; ${ }^{2}$ Cleveland Biolabs, Inc., Buffalo, New York 14052, USA; ${ }^{3}$ University Hospitals Case Medical Center, Case Western Reserve University School of Medicine. Cleveland, Ohio 44106, USA

A critical aspect of mammalian development involves the actions of dedicated repressors/corepressors to prevent unregulated gene activation programs that would initiate specific cell determination events. While the role of NCoR/SMRT corepressors in nuclear receptor actions is well documented, we here report that a previously unrecognized functional interaction between SMRT and a forkhead protein, FOXP1, is required for cardiac growth and regulation of macrophage differentiation. Our studies demonstrate that SMRT and FOXP1 define a functional biological unit required to orchestrate specific programs critical for mammalian organogenesis, linking developmental roles of FOX to a specific corepressor.

Supplemental material is available at http://www.genesdev.org.

Received November 27, 2007; revised version accepted January 18, 2008.

Although activation of transcription has long been recognized as an essential component of gene regulation during development, the critical role of transcriptional repression programs is apparent from the pluripotent stem cell to terminal differentiation events. Nuclear receptors, including retinoic acid and thyroid hormone receptors (RAR and $T_{3} R$ ), regulate development through both ligand-dependent activation and active repression by unliganded nuclear receptors /Glass and Rosenfeld 2000 ), and their ability to actively repress transcription in the absence of their cognate ligands is conferred by their interaction with SMRT or with the highly related corepressor NCoR (Chen and Evans 1995; Horlein et al. 1995). NCoR and SMRT also confer transcriptional repression to many additional members of the nuclear receptor superfamily, as well as on a variety of unrelated transcription factors, at least in part due to corecruitment of histone deacetylase proteins (HDACs) (Privalsky 2001; Jepsen and Rosenfeld 2002; Jones and Shi 2003).

[Keywords: SMRT; FOXP1; corepressor; heart; macrophage]

Corresponding authors.

${ }^{4}$ E-MAIL mrosenfeld@ucsd.edu; FAX (858) 534-8180.

${ }^{5}$ E-MAIL jepsen@ucsd.edu; FAX (858) 534-8180.

Article is online at http://www.genesdev.org/cgi/doi/10.1101/gad.1637108.
The forkhead family of transcription factors, which includes over a hundred genes in several species named for the forkhead-box (FOX) DNA-binding domain, has been characterized as both transcriptional activators and repressors (for review, see Wijchers et al. 2006). While all four FoxP family members function as transcriptional repressors, the mechanism of this repression remains largely uncharacterized, although FoxP3 has been shown to be capable of interacting with HDAC proteins ( $\mathrm{Li}$ et al. 2007). Gene deletion studies have revealed that FOXP1 mutant mice have defects in cardiac morphogenesis, a thin ventricular myocardial compact zone, and lack of proper ventricular septation, which together result in embryonic death at embryonic day 14.5 (E14.5) (Wang et al. 2004). Interestingly, maintaining the proper balance of histone acetylation/deacetylation is critical for proper cardiac development and growth (Backs and Olson 2006; Montgomery et al. 2007), leading us to consider potential links between FOXP1 and recruitment of specific corepressor complexes.

Here we report that deletion of the gene encoding the corepressor SMRT resulted in specific developmental abnormalities including hypoplasia of the ventricular chambers of the heart and a defect in ventricular septation, accompanied by up-regulation of the CDK inhibitor p21 (WAF-1/CIP-1/SDI-1), a phenotype analogous to that reported for gene deletion of FOXP1. We found that both SMRT and FOXP1 are recruited to the $p 21$ promoter, and that these proteins physically interact. $S M R T^{+/-}$ $F O X 1^{+/-}$double heterozygote mice exhibit a phenotype comparable with either single gene deletion, suggesting that, together, SMRT and FOXP1 regulate a program of gene repression essential to proper myocardial development. This SMRT/FOXP1 corepressor complex appears to mediate a more general strategy, as SMRT and FOXP1 proteins prove to be a component of $c$-fms regulation in monocytes, indicating that SMRT-mediated corepression may be a common mechanism by which FOXP1 and other FOX proteins regulate gene expression programs in development of target organs.

\section{Results and Discussion}

\section{Characterization of $\mathrm{SMRT}^{-/-}$cardiac defect}

$S M R T$ gene-deleted mice initially generated and analyzed for defects in neural development in Jepsen et al. (2007) were analyzed to delineate potential roles of SMRT independent of its actions on nuclear receptors. We observed that the majority of $S M R T^{-/-}$mice died by E16.5. Histological examination of E14.5 embryonic hearts revealed a hypoplastic ventricular wall and a defect in ventricular septation (Fig. 1A-D), detectable as early as E11.5 (Fig. 1E-H). The transformation of the ventricular chamber from the thin-walled state observed at E9.5 to the mature ventricle requires two distinct waves of proliferation that are accompanied by morphogenic changes, both beginning around E9.5-E10.5. The proliferating myocardium on the endocardial (inner) side of the ventricles becomes the trabecular layer while the proliferating myocardium on the epicardial (outer) side of the ventricles forms the compact zone. Further expansion of the compact zone allows for formation of the interventricular septum by cardiomyocytes. Genetic 


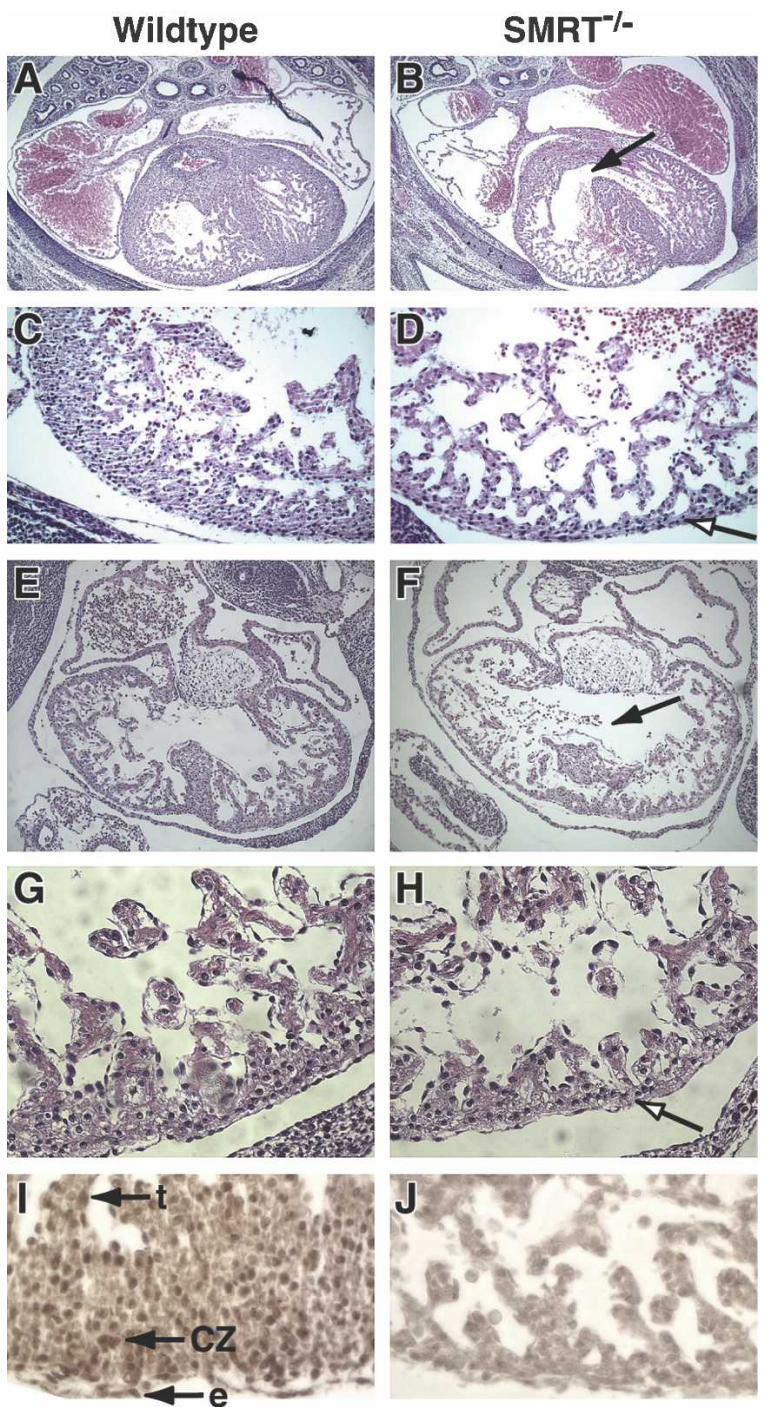

Figure 1. Gene deletion of SMRT results in a severe heart defect. $(A-H)$ Low-power $(A, B, E, F)$ and high-power $(C, D, G, H)$ photomicrographs of H\&E-stained transverse cryo-sections of control and $S M R T^{-/-}$heart reveal thinned ventricular walls (open arrow) and a ventricular septum defect (filled arrow) in $S M R T^{-1-}$ hearts as observed at E14.5 $(A-D)$ and E11.5 $(E-H) .(I, J)$ High-power photomicrographs of E15.5 wild-type $(I)$ or $S M R T^{-/-}(J)$ hearts stained with an antibody specific for SMRT indicating expression in trabeculae $(t)$, compact zone (cz), and epicardium (e).

mutations affecting compact zone formation cause embryonic lethality beginning around E14.5, consistent with the timing of death observed in $S M R T^{-/-}$mice (Fig. 2E). Radioactive in situ analysis using probes to cardiac $\alpha$-actin, the ventricular-specific myosin light chain $2 \mathrm{v}$ $(M L C 2 V)$ and atrial-specific myosin light chain $2 \mathrm{a}$ (MLC2a) detected no differences between wild-type or $S M R T^{-/-}$hearts at E14.5, suggesting that initial cardiac and chamber specification occurred normally (data not shown).

\section{$S M R T$ is required in cardiac myocardium}

The mature heart originates mainly from four separate tissues (neural crest, myocardium, endocardium, epicardium). In addition to the myocardial cell themselves, signals from the epicardium to the myocardium play an essential role in ventricular wall compact zone expansion (Kreidberg et al. 1993; Kwee et al. 1995; Yang et al. 1995; Chen et al. 2002; Pennisi et al. 2003), while neither endocardium nor neural crest has been implicated. The phenotype observed for $S M R T^{-/-}$embryos was strikingly similar to the heart phenotype reported previously for Retinoid X Receptor $\alpha(R X R \alpha)$ gene-deleted mice (Kastner et al. 1994; Sucov et al. 1994) that has been reported to be independent of $\mathrm{RXR} \alpha$ expression in myocytes (Chen et al. 1998; Tran and Sucov 1998; Subbarayan et al. $2000 \mathrm{~b}$ ) but to require $\mathrm{RXR} \alpha$ in the epicardium (Chen et al. 2002). As SMRT has been reported to interact with $\mathrm{RXR} \alpha$ to repress transcription (Ghosh et al. 2002), and as expression of SMRT protein was specifically detected in both epicardium and myocardium, as well as in trabeculae and endocardium (Fig. 1I,J), we sought to determine whether or not SMRT was required in a cell-autonomous manner.

To this end, we generated transgenic mice in which myocyte-specific expression of a dominant-negative SMRT protein was driven by the $\alpha$-myosin heavy-chain $(\alpha-\mathrm{MHC})$ promoter (Subramaniam et al. 1991). The region of SMRT chosen as a dominant negative is based on previously published reports (Feng et al. 2001; Koide et al. 2001) and consists of the region C-terminal to the repressor domains (amino acids 1500 through the stop codon) (Supplemental Fig. 1A). Pronuclear injection of linearized HA-tagged $\alpha-M H C-D N-S M R T$ was performed, and litters were sacrificed at E13.5, E14.5, or E15.5 for transgenic founder analysis. Significant embryonic lethality was observed at both E14.5 and E15.5 (18\% and $20 \%$ of all embryos recovered, respectively), and rates of positive transgene recovery also fell with embryonic age (Supplemental Fig. 1B), suggesting that the embryonic lethality was associated with expression of the DNSMRT transgene. Indeed, expression of DN-SMRT in the myocardium using the $\alpha-M H C$ promoter resulted in a phenotype at E13.5 that was analogous to that of the SMRT gene-deleted mice in that the compact zone was reduced in thickness and there were ventricular septation defects (cf. Figs. 1A-D and 2A-D). As the $\alpha-M H C$ promoter drives expression specifically in cardiomyocytes (Subramaniam et al. 1991), these data suggest that the requirement for SMRT is cell-autonomous. To provide further evidence of the cell-autonomous role for SMRT, we tested whether transgenic re-expression of $S M R T$ in mutant cardiac myocytes could rescue these defects (Supplemental Fig. 1A). Indeed, the SMRT gene deletion phenotype was rescued by the expression of fulllength SMRT in myocardium as evidenced by increased survival at later embryonic ages (Fig. 2E). Additionally, $\alpha-M H C$-SMRT-rescued $S M R T^{-/}$embryos have an intact ventricular septum and a compact zone thickness that nears that of wild-type embryos (Fig. 2F,G). Survival after birth was precluded by the presence of a severe secondary palate defect that was not rescued by the cardiomyoctye-specific expression of SMRT (Jepsen et al. 2007). In contrast, overexpression of the non-cell-autonomous $R X R \alpha$ in $R X R \alpha^{-/-}$mice using the $\alpha-M H C$ promoter did not prevent either fetal lethality or the myocardial defects observed in these mice (Subbarayan et al. 2000a).

\section{SMRT interacts with FOXP1}

That the $S M R T^{-/-}$cardiac phenotype was cell-autonomous essentially precluded the hypothesis that SMRT 

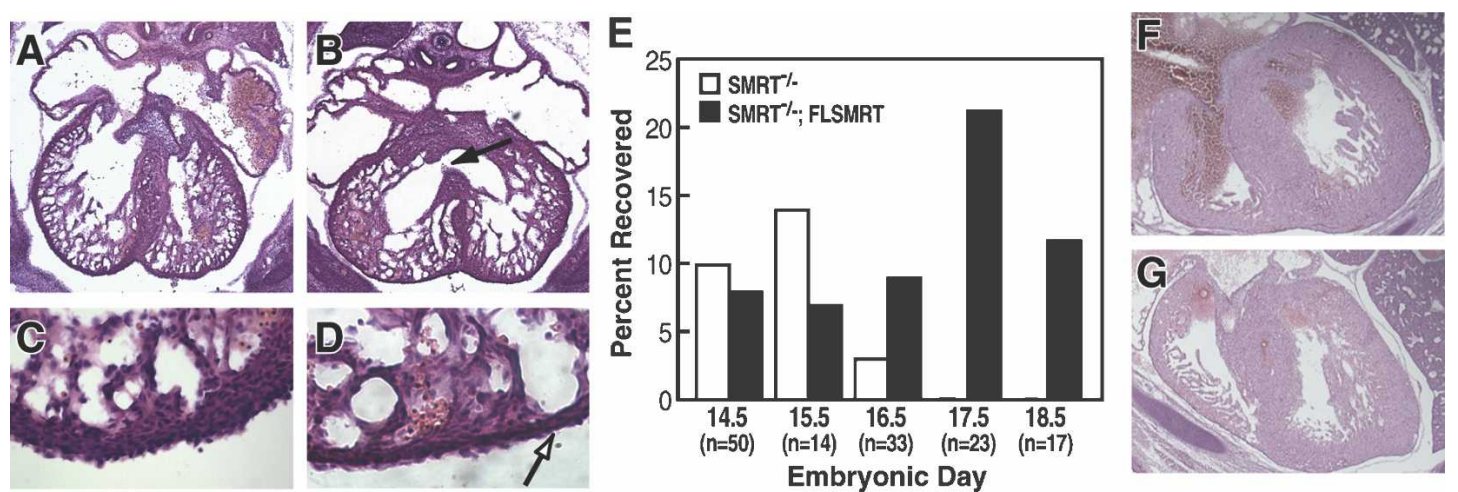

Figure 2. The requirement for SMRT in heart development is cell-autonomous. $(A-D)$ Low-power $(A, B)$ and high-power $(C, D)$ photomicrographs of H\&E-stained transverse cryo-sections from E13.5 wild-type $(A, C)$ and transgenic $(B, D)$ hearts expressing dominant-negative SMRT driven by $\alpha-M H C(\alpha-M H C-D N-S M R T)$ revealed thinned ventricular walls (open arrow) and a ventricular septum defect (filled arrow) in transgenics. (E) Summary of live embryos recovered from $S M R T^{+/-}$mice crossed to $\alpha-M H C-F L-S M R T^{+} / S M R T^{+/-}$mice at various ages. $(F, G)$ Low-power photomicrographs of H\&E-stained transverse cryo-sections from E17.5 wild-type $(F)$ or $\alpha-M H C-F L-S M R T^{+} / S M R T^{-/-}(G)$ hearts.

was acting exclusively by repressing $\mathrm{RXR} \alpha$ gene targets. We were, therefore, particularly intrigued by a report that gene deletion of FOXP1 results in a myriad of heart defects, including a thinned compact zone and ventricular septal defect similar to what was observed for $S M R T^{-/-}$mice (Wang et al. 2004). As FOXP1 has been characterized as a DNA-binding transcriptional repressor (Shu et al. 2001; Wang et al. 2003), we wanted to test the possibility that SMRT could act as a functional corepressor with FOXP1 in heart, such that ablation of either factor would produce a similar phenotype. Coimmunoprecipitation experiments revealed that FOXP1 and SMRT interact both when overexpressed in HEK 293 cells (Fig. 3A) and in hearts dissected from E13.5 embryos (Fig. 3B). FOXP1 could also interact with both fulllength SMRT and the dominant-negative form of SMRT used to create the phenocopying transgene in GST-TNT assays (Fig. 3C). This is consistent with the idea that in vivo, overexpressed DN-SMRT interacts with FOXP1 and potentially prevents recruitment of wild-type SMRT, thus phenocopying the cardiac defect observed in the absence of SMRT.

Several genes have been implicated in the proliferation and differentiation of myocytes during embryonic development. Quantitative RT-PCR (qRT-PCR) was used to compare expression of p21, p27, and p57 between wildtype and $S M R T^{-/-}$hearts. While significant differences were not observed for $p 27$ or $p 57, p 21 \mathrm{mRNA}$ levels were up-regulated in $S M R T^{-/-}$hearts (Fig. 3D), a finding also reported for $F O X P 1^{-/-}$hearts (Wang et al. 2004). Expression of FOXP1 itself was unchanged in $S M R T^{-/-}$hearts compared with wild type (Fig. 3D). p21 has been identified as regulated directly by the FOX family of transcription factors, including FoxGI and FoxO in neuroepithelial and glioblastoma cells, through a conserved Fox consensus binding site at -1930 in the mouse $p 21$ promoter (Seoane et al. 2004). To determine whether FOXP1 and SMRT were recruited to the $p 21$ promoter during heart development, we isolated E10.5 myocardium from wildtype embryos and performed chromatin immunoprecipitation (ChIP) assays using antibodies specific to FOXP1 or SMRT. PCR amplification using oligonucleotides surrounding the Fox-binding site identified in the $p 21$ promoter revealed enrichment of both FOXP1 and SMRT on this promoter, as well as dimethylated histone H3 Lys 9
(DimeH3K9) (Fig. 3E), a mark associated with repression of p21 (Nishio and Walsh 2004; Duan et al. 2005). In contrast, the natriuretic peptide precursor type $\mathrm{A}(A N F)$ promoter region was assayed as a control and was positive only for DimeH3K9 (Fig. 3E). Increases in p21 levels have been reported to be correlated with the exit from cell cycle that occurs in the neonatal heart and with differentiation of cultured cardiomyocytes (Flink et al. 1998; Koh et al. 1998). Thus, it is logical to think that up-regulation of $p 21$ might result in a block in cell proliferation that could account for the thinned myocardium observed in $\mathrm{SMRT}^{-/}$and $\mathrm{FOXP1}^{-/-}$embryos. To evaluate changes in myocardial cell proliferation, we used antibodies to phospho-histone-H3 (PO4-H3), which labels cells undergoing mitosis. No differences in the number of PO4-H3-positive cells at E10.5, E11.5, E12.5, or E13.5 were observed, either in compact or trabecular zones, and we could find no evidence of increased apoptosis at these ages (data not shown). Interestingly, $\mathrm{FOXP}^{-/-}$embryos exhibited no change in PO4-H3 expression in the compact zone at E13.5 and an increase in PO4-H3 expression in the trabecular zone (Wang et al. 2004), suggesting that the etiology of this heart defect is complex.

\section{SMRT/FOXP1 double heterozygote mice mimic the cardiac defect observed in either single gene-deleted animal}

To test whether there was a genetic interaction between $S M R T$ and FOXP1, an embryonic stem (ES) cell clone with a retroviral gene trap insertion in the FOXP1 gene lobtained from the Soriano Laboratory Gene Trap Resource at the Fred Hutchinson Cancer Research Center) was used to generate mice heterozygote for FOXP1. Heterozygote FOXP1 mice were then interbred, and histological analysis confirmed that E14.5 FOXP1-/- embryonic hearts had the same ventricular septation defect and thinned compact zone phenotype originally observed for FOXP1 ${ }^{-/-}$(Supplemental Fig. 1C,D; Wang et al. 2004). $S M R T^{+/-}$mice were then interbred with $F O X P 1^{+/-}$animals to generate $S M R T^{+/-} / F O X P 1^{+/-}$double heterozygotes. While $S M R T^{+/-}, F O X P 1^{+/-}$, and wild-type animals were all recovered at near the $25 \%$ expected Mendelian rate, $S M R T^{+/-} / F_{X X P 1^{+/-}}$double heterozygotes were re- 


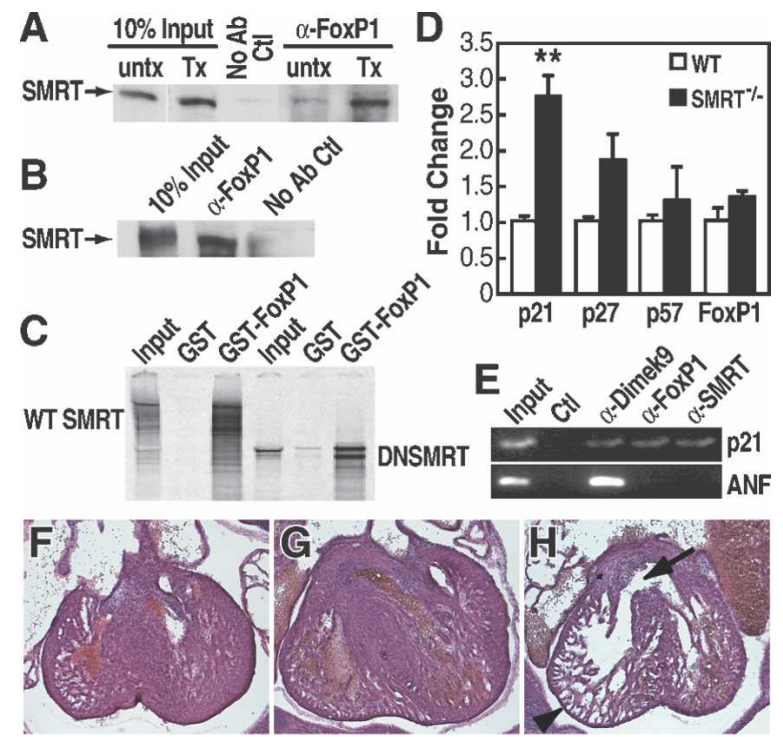

Figure 3. SMRT and FOXP1 interact in the heart to regulate proper heart development. Coimmunoprecipitation of SMRT and FOXP1 in HEK 293 cells $(A)$ and in E13.5 hearts $(B)$. $(C)$ Interaction of ${ }^{35} \mathrm{~S}$ radiolabeled wild-type SMRT or DN-SMRT (amino acids 1500 through the stop codon) with GST-FOXP1 fusion protein or GST protein alone. (D) qRT-PCR for p21, p27, p57, and FOXP1 on cDNA isolated from E10.5 wild-type or $S M R T^{-/-}$hearts $( \pm$standard error of the mean, SEM; $\left.{ }^{\left.{ }^{*}\right]} P<0.005\right)$. (E) ChIP analysis on E10.5 hearts using specific anti-SMRT, anti-FOXP1, and anti-histone H3 dimethyl K9 antibodies and oligonucleotides surrounding the FOX-binding site of the p21 promoter. $(F-H)$ Photomicrographs of H\&E-stained transverse cryo-sections from $F O X P 1^{+/-}(F), S M R T^{+/-}(G)$, and $\mathrm{FOXP1}^{+/-} / \mathrm{SMRT}^{+/-}(H)$ E14.5 embryos. Arrowhead indicates thinned ventricular wall. Arrow indicates ventricular septum defect. (Tx) Transfected; (UnTx) untransfected; (ANF) natriuretic peptide precursor type A.

covered at a rate of just $10 \%$, suggesting embryonic lethality. Histological analysis of embryos generated from $F O X P 1^{+/-}$crossed to $S M R T^{+/-}$at E14.5 revealed that $\sim 50 \%$ of $\mathrm{FOXP1}^{+/-} / \mathrm{SMRT}^{+/-}$double heterozygote embryos had a thinned myocardium and ventricular septal defect similar to that observed for gene deletion of either factor alone (Fig. 3H). As such a phenotype was not observed for single heterozygote animals (Fig. 3F,G), this provides genetic evidence of a $S M R T^{+/-} / F O X P 1^{+/-}$interaction in heart development.

\section{SMRT mediates FOXP1 repression of $\mathrm{c}-\mathrm{fms}$ in a monocyte cell line}

To determine if SMRT can serve as a corepressor for FOXP1 in cells other than myocardium, we investigated the role of SMRT in regulating expression of $c$-fms, which encodes the colony-stimulating factor 1 receptor (Csf1r), a receptor-tyrosine kinase responsible for the differentiation and maturation of macrophages. Transcriptional repression of $c$ - $f m s$ in undifferentiated THP-1 cells has been reported to be mediated by FOXP1, and overexpression of FOXP1 during the differentiation process delays induction of $c$-fms with the protein kinase $\mathrm{C}$ activator phorbol myristate acetate (PMA) (Shi et al. 2004). Lipofection of two distinct siRNAs specific for $S M R T$ (Supplemental Fig. 1E) consistently increased expression of $c$-fms (Fig. 4A), suggesting that SMRT can act as a corepessor of FOXP1 in repression of $c$-fms. SiRNA spe- cific for FOXP1 (Supplemental Fig. 1H) also resulted in a significant increase in $c$-fms expression (Fig. 4A). However, we note that the fold induction of $c-f m s$ with siRNA-mediated removal of SMRT or FOXP1 is not as great as that observed when THP-1 cells are treated with PMA (Supplemental Fig. S1F), suggesting that to fully activate $c$-fms gene transcription in this assay, a specific activation signal in addition to removal of a repressor complex may be required as has been demonstrated in the case of the RAR (Ogawa et al. 2004). Alternatively, as lipofection of control siRNA results in increased $c$-fms gene expression compared with nonlipofected cells (Supplemental Fig. S1G), it is possible that the $c-f m s$ induction observed with siRNAs specific for $S M R T$ or FoxP1 is dampened by the increased baseline of $c$-fms expression.

To determine whether FOXP1 and SMRT can directly repress $c$-fms, we performed ChIP assays using primers surrounding the previously identified FOXP1-binding sites in the $c$-fms promoter (Shi et al. 2004). Both FOXP1 and SMRT were detected as bound to the $c$-fms promoter in untreated cells, but not in cells treated with PMA (Fig. 4B-D), consistent with the fact that PMA induces $c$-fms expression (Supplemental Fig. 1F; Shi et al. 2004). To
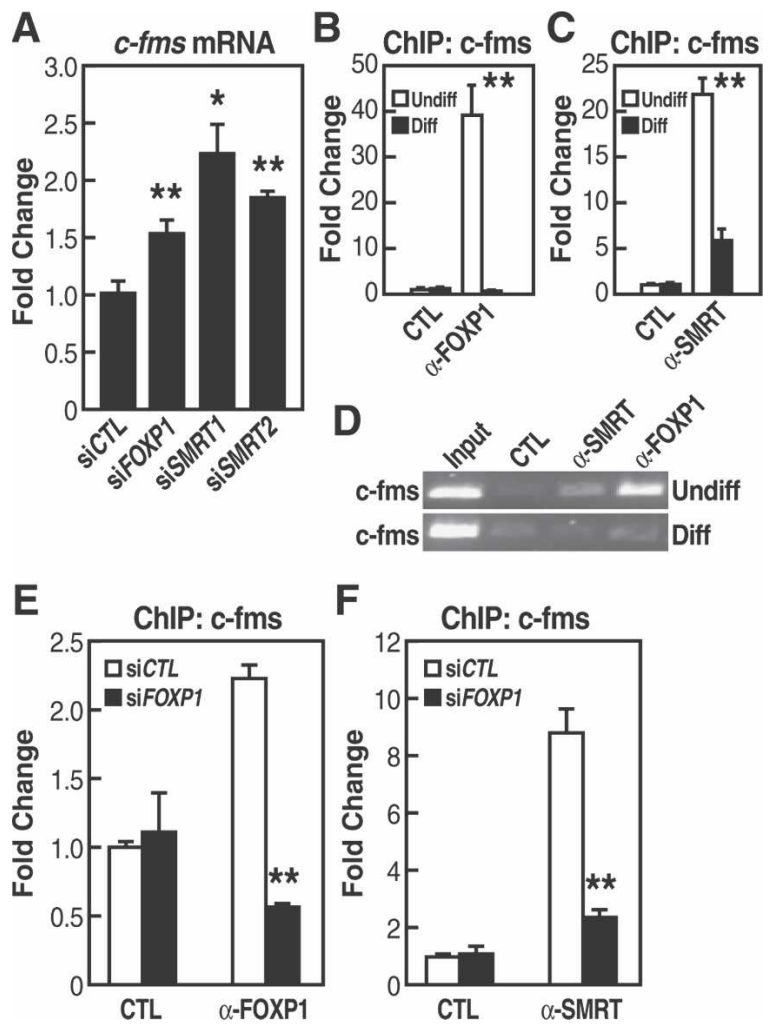

Figure 4. SMRT and FOXP1 coregulate $c$-fms expression in THP-1 cells. (A) Effect of siRNAs specific to FOXP1 or SMRT on $c$-fms mRNA levels as measured by qRT-PCR $\left({ }_{ \pm} \mathrm{SEM}_{i}\left[{ }^{\star}\right] P<0.01,\left[{ }^{* \star}\right]\right.$ $P<0.005) .(B, C)$ qPCR analysis of chromatin-immunoprecipitated SMRT or FOXP1 on untreated (undiff) and PMA-treated (diff) THP-1 cells using specific anti-SMRT and anti-FOXP1 antibodies and oligonucleotides surrounding the FOX-binding site of the $c$-fms promoter. $(D)$ Agarose gel representation of ChIP analysis in $B$ and $C$. $(E, F) \mathrm{qPCR}$ analysis of chromatin-immunoprecipitated SMRT or FOXP1 using oligonucleotides surrounding the FOX-binding site of the $c$-fms promoter performed on THP-1 cells lipofected with FOXP1 siRNA. 
determine whether FOXP1 is itself responsible for recruitment of SMRT, we performed ChIP analysis in THP-1 cells following treatment with specific siRNA for FOXP1 (Supplemental Fig. 1H). Indeed, neither FOXP1 nor SMRT was detected on the $c$-fms promoter in the absence of FOXP1 (Fig. 4E,F). This indicates that SMRT is recruited to $c$-fms promoter specifically through interactions with FOXP1. Together these data indicate that the function of the SMRT/FOXP1 unit extends to a second biological system, suggesting a more general mechanism whereby FOXP1 repression programs depend on SMRT corepression.

Transcriptional activation and repression mediated by sequence-specific DNA-binding factors underlie the binary decisions necessary for progression of cell determination events, and it is increasingly clear that cofactors, including NCoR and SMRT, are indispensable for proper development in a variety of developmental systems. Interestingly, despite their high homology, NCoR and SMRT appear to have nonoverlapping roles in many instances, with NCoR gene-deleted mice exhibiting defects in developmental progression of erythrocytes and thymocytes (Jepsen et al. 2000). Neural stem cells (NSCs) isolated from either gene-deleted mouse exhibit spontaneous differentiation into astrocytes, but only SMRT is required for repression of neuronal differentiation (Hermanson et al. 2002; Jepsen et al. 2007). Interestingly, in NSCs, we found that SMRT was required to repress an RAR-dependent differentiation program (Jepsen et al. 2007). Here we propose a novel role for SMRT in regulating heart development through a forkhead protein as SMRT is required to cell-autonomously regulate growth of the ventricular compact zone, distinct from the requirement for $\mathrm{RXR} \alpha$ in epicardium (Chen et al. 2002). Indeed, as SMRT and FOXP1 both appear to be used for gene regulation in heart and macrophages, we can suggest that this is a general mechanism by which FOXP1, and perhaps other family members of this forkhead protein subclass, mediate transcription. Thus we have demonstrated that the previously unrecognized relationship between SMRT and a forkhead family member underlies multiple biological programs.

\section{Materials and methods}

\section{Immunoprecipitation}

HEK 293 cells were transfected with pCMX-SMRT (mouse) and pcDNAFOXP1 (human) using Lipofectamine 2000 (Invitrogen). For immunoprecipitations from heart, the ventricles of $\sim 50$ hearts were dissected from E10.5 mouse embryos. Immunoprecipitations were performed as described previously (Heinzel et al. 1997) using anti-FOXP1 antibodies (Shi et al. 2004).

\section{Protein interaction assays}

Full-length or DN-SMRT were in vitro translated using the TNT QuickCoupled Transcription/Translation System (Promega). A GST-FOXP1 fusion protein was generated from a pGEX vector containing human FOXP1 cDNA in frame with GST. GST-TNT interaction assays were performed essentially as described previously (Olson et al. 2006).

\section{ChIP}

ChIP was performed as described previously (Jepsen et al. 2000). Ten E10.5 dissected hearts or $10^{7}$ THP-1 cells were used per antibody, using $1 \mu \mathrm{g}$ of the following antibodies: SMRT (Affinity Bioreagents, PA1-843); FOXP1 (AVIVA Systems Biology, ARP32564; and CeMines, AB/FOX330, pooled); dimethyl histone H3 K9 (Upstate Biotechnology, 07-441). See the Supplemental Material for the primers used.
FOXP1 gene-deleted mice

ES cell line S17-4A, which features insertion of a retroviral gene trap vector into the fifth intron of FOXP1 (NT_039353), was kindly provided by Philippe Soriano and was used to generate FOXP1 gene-deleted mice. Genotypes were determined by PCR analysis (see the Supplemental Material).

\section{Acknowledgments}

We thank H. Taylor for animal care, C. Nelson for cell culture assistance, J. Hightower for artwork, M. Fisher for assistance with the manuscript, F. Liu for $S M R T^{+/-}$ES cell blastocyst injection, J. Gulick for the $\alpha-M H C$ promoter construct, and the UCSD Transgenic Mouse and Gene Targeting Core for pronuclear microinjection of $\alpha-M H C-D N-S M R T$ and $\alpha-M H C-F L-S M R T$ and for FOXP1+/- ES cell blastocyst injection. M.G.R. is an investigator with HHMI. This work was funded by a Scientist Development Grant from the American Heart Association to K.J.; by NIH grants HL057506, HL085816, and HL073852 to D.I.S.; and by grants from the NIH to M.G.R.

\section{References}

Backs, J. and Olson, E.N. 2006. Control of cardiac growth by histone acetylation/deacetylation. Circ. Res. 98: 15-24.

Chen, J.D. and Evans, R.M. 1995. A transcriptional co-repressor that interacts with nuclear hormone receptors. Nature 377: 454-457.

Chen, J., Kubalak, S.W., and Chien, K.R. 1998. Ventricular muscle-restricted targeting of the $\mathrm{RXR} \alpha$ gene reveals a non-cell-autonomous requirement in cardiac chamber morphogenesis. Development 125: 1943-1949.

Chen, T.H., Chang, T.C., Kang, J.O., Choudhary, B., Makita, T., Tran, C.M., Burch, J.B., Eid, H., and Sucov, H.M. 2002. Epicardial induction of fetal cardiomyocyte proliferation via a retinoic acid-inducible trophic factor. Dev. Biol. 250: 198-207.

Duan, Z., Zarebski, A., Montoya-Durango, D., Grimes, H.L., and Horwitz, M. 2005. Gfil coordinates epigenetic repression of p21Cip/ WAF1 by recruitment of histone lysine methyltransferase G9a and histone deacetylase 1. Mol. Cell. Biol. 25: 10338-10351.

Feng, X., Jiang, Y., Meltzer, P., and Yen, P.M. 2001. Transgenic targeting of a dominant negative corepressor to liver blocks basal repression by thyroid hormone receptor and increases cell proliferation. I. Biol. Chem. 276: 15066-15072.

Flink, I.L., Oana, S., Maitra, N., Bahl, J.J., and Morkin, E. 1998. Changes in E2F complexes containing retinoblastoma protein family members and increased cyclin-dependent kinase inhibitor activities during terminal differentiation of cardiomyocytes. J. Mol. Cell. Cardiol. 30: 563-578.

Ghosh, J.C., Yang, X., Zhang, A., Lambert, M.H., Li, H., Xu, H.E., and Chen, J.D. 2002. Interactions that determine the assembly of a retinoid X receptor/corepressor complex. Proc. Nat1. Acad. Sci. 99: 58425847.

Glass, C.K. and Rosenfeld, M.G. 2000. The coregulator exchange in transcriptional functions of nuclear receptors. Genes \& Dev. 14: 121-141.

Heinzel, T., Lavinsky, R.M., Mullen, T.M., Soderstrom, M., Laherty, C.D., Torchia, J., Yang, W.M., Brard, G., Ngo, S.D., Davie, J.R., et al. 1997. A complex containing $\mathrm{N}-\mathrm{CoR}, \mathrm{mSin} 3$ and histone deacetylase mediates transcriptional repression. Nature 387: 43-48.

Hermanson, O., Jepsen, K., and Rosenfeld, M.G. 2002. N-CoR controls differentiation of neural stem cells into astrocytes. Nature 419: 934939.

Horlein, A.J., Naar, A.M., Heinzel, T., Torchia, J., Gloss, B., Kurokawa, R., Ryan, A., Kamei, Y., Soderstrom, M., Glass, C.K., et al. 1995. Ligand-independent repression by the thyroid hormone receptor mediated by a nuclear receptor co-repressor. Nature 377: 397-404.

Jepsen, K. and Rosenfeld, M.G. 2002. Biological roles and mechanistic actions of co-repressor complexes. J. Cell Sci. 115: 689-698.

Jepsen, K., Hermanson, O., Onami, T.M., Gleiberman, A.S., Lunyak, V., McEvilly, R.J., Kurokawa, R., Kumar, V., Liu, F., Seto, E., et al. 2000. Combinatorial roles of the nuclear receptor corepressor in transcription and development. Cell 102: 753-763.

Jepsen, K., Solum, D., Zhou, T., McEvilly, R.J., Kim, H.-J., Glass, C.K., Hermanson, O., and Rosenfeld, M.G. 2007. SMRT-mediated repression of an H3K27 demethylase in progression from neural stem cell to 
neuron. Nature 450: 415-419.

Jones, P.L. and Shi, Y.B. 2003. N-CoR-HDAC corepressor complexes: Roles in transcriptional regulation by nuclear hormone receptors. Curr. Top. Microbiol. Immunol. 274: 237-268.

Kastner, P., Grondona, J.M., Mark, M., Gansmuller, A., LeMeur, M., Decimo, D., Vonesch, J.L., Dolle, P., and Chambon, P. 1994. Genetic analysis of RXR $\alpha$ developmental function: Convergence of RXR and RAR signaling pathways in heart and eye morphogenesis. Cell 78: 987-1003.

Koh, K.N., Kang, M.J., Frith-Terhune, A., Park, S.K., Kim, I., Lee, C.O., and Koh, G.Y. 1998. Persistent and heterogenous expression of the cyclin-dependent kinase inhibitor, p27KIP1, in rat hearts during development. J. Mol. Cell. Cardiol. 30: 463-474.

Koide, T., Downes, M., Chandraratna, R.A., Blumberg, B., and Umesono, K. 2001. Active repression of RAR signaling is required for head formation. Genes \& Dev. 15: 2111-2121.

Kreidberg, J.A., Sariola, H., Loring, J.M., Maeda, M., Pelletier, J., Housman, D., and Jaenisch, R. 1993. WT-1 is required for early kidney development. Cell 74: 679-691.

Kwee, L., Burns, D.K., Rumberger, J.M., Norton, C., Wolitzky, B., Terry, R., Lombard-Gillooly, K.M., Shuster, D.J., Kontgen, F., Stewart, C., et al. 1995. Creation and characterization of E-selectin- and VCAM-1deficient mice. Ciba Found. Symp. 189: 17-28.

Li, B., Samanta, A., Song, X., Iacono, K.T., Bembas, K., Tao, R., Basu, S., Riley, J.L., Hancock, W.W., Shen, Y., et al. 2007. FOXP3 interactions with histone acetyltransferase and class II histone deacetylases are required for repression. Proc. Nat1. Acad. Sci. 104: 4571-4576.

Montgomery, R.L., Davis, C.A., Potthoff, M.J., Haberland, M., Fielitz, J., Qi, X., Hill, J.A., Richardson, J.A., and Olson, E.N. 2007. Histone deacetylases 1 and 2 redundantly regulate cardiac morphogenesis, growth, and contractility. Genes \& Dev. 21: 1790-1802.

Nishio, H. and Walsh, M.J. 2004. CCAAT displacement protein/cut homolog recruits G9a histone lysine methyltransferase to repress transcription. Proc. Nat1. Acad. Sci. 101: 11257-11262.

Ogawa, S., Lozach, J., Jepsen, K., Sawka-Verhelle, D., Perissi, V., Sasik, R., Rose, D.W., Johnson, R.S., Rosenfeld, M.G., and Glass, C.K. 2004. A nuclear receptor corepressor transcriptional checkpoint controlling activator protein 1-dependent gene networks required for macrophage activation. Proc. Natl. Acad. Sci. 101: 14461-14466.

Olson, L.E., Tollkuhn, J., Scafoglio, C., Krones, A., Zhang, J., Ohgi, K.A., Wu, W., Taketo, M.M., Kemler, R., Grosschedl, R., et al. 2006. Homeodomain-mediated $\beta$-catenin-dependent switching events dictate cell-lineage determination. Cell 125: 593-605.

Pennisi, D.J., Ballard, V.L., and Mikawa, T. 2003. Epicardium is required for the full rate of myocyte proliferation and levels of expression of myocyte mitogenic factors FGF2 and its receptor, FGFR-1, but not for transmural myocardial patterning in the embryonic chick heart. Dev. Dyn. 228: 161-172.

Privalsky, M.L. 2001. Regulation of SMRT and N-CoR corepressor function. Curr. Top. Microbiol. Immunol. 254: 117-136.

Seoane, J., Le, H.V., Shen, L., Anderson, S.A., and Massague, J. 2004. Integration of Smad and forkhead pathways in the control of neuroepithelial and glioblastoma cell proliferation. Cell 117: 211-223.

Shi, C., Zhang, X., Chen, Z., Sulaiman, K., Feinberg, M.W., Ballantyne, C.M., Jain, M.K., and Simon, D.I. 2004. Integrin engagement regulates monocyte differentiation through the forkhead transcription factor Foxpl. J. Clin. Invest. 114: 408-418.

Shu, W., Yang, H., Zhang, L., Lu, M.M., and Morrisey, E.E. 2001. Characterization of a new subfamily of winged-helix/forkhead (Fox) genes that are expressed in the lung and act as transcriptional repressors. J. Biol. Chem. 276: 27488-27497.

Subbarayan, V., Mark, M., Messadeq, N., Rustin, P., Chambon, P., and Kastner, P. 2000a. RXR $\alpha$ overexpression in cardiomyocytes causes dilated cardiomyopathy but fails to rescue myocardial hypoplasia in RXR $\alpha$-null fetuses. J. Clin. Invest. 105: 387-394.

Subbarayan, V., Mark, M., Messadeq, N., Rustin, P., Chambon, P., and Kastner, P. 2000b. RXR $\alpha$ overexpression in cardiomyocytes causes dilated cardiomyopathy but fails to rescue myocardial hypoplasia in RXR $\alpha$-null fetuses. J. Clin. Invest. 105: 387-394.

Subramaniam, A., Jones, W.K., Gulick, J., Wert, S., Neumann, J., and Robbins, J. 1991. Tissue-specific regulation of the $\alpha$-myosin heavy chain gene promoter in transgenic mice. J. Biol. Chem. 266: 24613 24620 .
Sucov, H.M., Dyson, E., Gumeringer, C.L., Price, J., Chien, K.R., and Evans, R.M. 1994. RXR $\alpha$ mutant mice establish a genetic basis for vitamin A signaling in heart morphogenesis. Genes \& Dev. 8: 10071018.

Tran, C.M. and Sucov, H.M. 1998. The RXR $\alpha$ gene functions in a noncell-autonomous manner during mouse cardiac morphogenesis. Development 125: 1951-1956.

Wang, B., Lin, D., Li, C., and Tucker, P. 2003. Multiple domains define the expression and regulatory properties of Foxpl forkhead transcriptional repressors. J. Biol. Chem. 278: 24259-24268.

Wang, B., Weidenfeld, J., Lu, M.M., Maika, S., Kuziel, W.A., Morrisey, E.E., and Tucker, P.W. 2004. Foxp1 regulates cardiac outflow tract, endocardial cushion morphogenesis and myocyte proliferation and maturation. Development 131: 4477-4487.

Wijchers, P.J., Burbach, J.P., and Smidt, M.P. 2006. In control of biology: Of mice, men and Foxes. Biochem. I. 397: 233-246.

Yang, J.T., Rayburn, H., and Hynes, R.O. 1995. Cell adhesion events mediated by $\alpha 4$ integrins are essential in placental and cardiac development. Development 121: 549-560. 


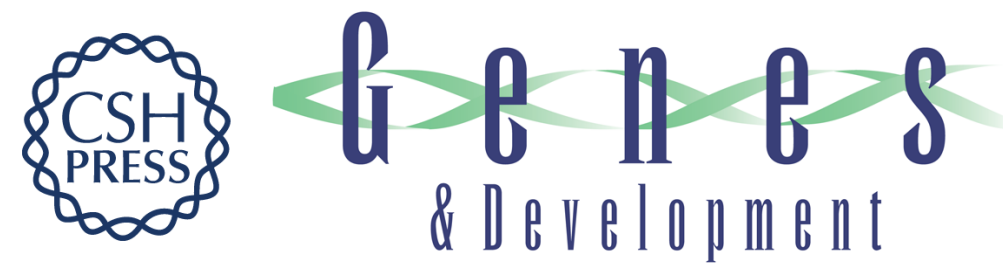

\section{Cooperative regulation in development by SMRT and FOXP1}

Kristen Jepsen, Anatoli S. Gleiberman, Can Shi, et al.

Genes Dev. 2008, 22:

Access the most recent version at doi:10.1101/gad.1637108

Supplemental

Material

References

This article cites 40 articles, 20 of which can be accessed free at: http://genesdev.cshlp.org/content/22/6/740.full.html\#ref-list-1

License Freely available online through the Genes \& Development Open Access option.

Email Alerting Receive free email alerts when new articles cite this article - sign up in the box at the top Service right corner of the article or click here.

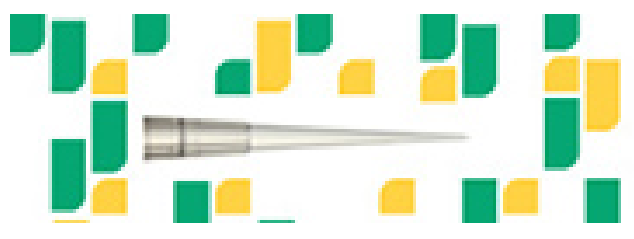

Focused on your science. 